\title{
Draft genome sequence of the type strain of the sulfur-oxidizing acidophile, Acidithiobacillus albertensis (DSM 14366)
}

\author{
Matías Castro ${ }^{1 \dagger}$, Ana Moya-Beltrán ${ }^{1 \dagger}$, Paulo C. Covarrubias ${ }^{1,5}$, Mónica Gonzalez ${ }^{1}$, Juan Pablo Cardenas ${ }^{1,5}$, \\ Francisco Issotta ${ }^{1}$, Harold Nuñez ${ }^{1,5}$, Lillian G. Acuña ${ }^{1}$, Gonzalo Encina ${ }^{2}$, David S. Holmes ${ }^{1,3}$, D. Barrie Johnson ${ }^{4}$ \\ and Raquel Quatrini ${ }^{1 *}$
}

\begin{abstract}
Acidithiobacillus albertensis is an extremely acidophilic, mesophilic, obligatory autotrophic sulfur-oxidizer, with potential importance in the bioleaching of sulfidic metal ores, first described in the 1980s. Here we present the draft genome sequence of Acidithiobacillus albertensis DSM $14366^{\top}$, thereby both filling a long-standing gap in the genomics of the acidithiobacilli, and providing further insight into the understanding of the biology of the non iron-oxidizing members of the Acidithiobacillus genus. The assembled genome is 3,1 Mb, and contains 47 tRNAs, tmRNA gene and 2 rRNA operons, along with 3149 protein-coding predicted genes. The Whole Genome Shotgun project was deposited in DDBJ/EMBL/GenBank under the accession MOAD00000000.
\end{abstract}

Keywords: Acidithiobacilli, Extreme acidophile, Sulfur oxidizer, Bioleaching, Sulfidic metal ores, Phylogenomics

\section{Introduction}

The genus Acidithiobacillus [1] comprises a group of obligatory acidophilic chemolithotrophic bacteria that derive energy from the oxidation of reduced sulfur compounds, thereby contributing to the bioleaching of ores and to the formation of polluting mine drainage waters. Although they were considered until relatively recently as members of the Gamma-proteobacteria, multi-protein phylogenetic analysis of concatenated ribosomal proteins re-categorized the order Acidithiobacillales as a new class of proteobacteria, now known as Acidithiobacillia [2]. Currently, seven species are recognized: Acidithiobacillus thiooxidans [3], A. ferrooxidans [4], A. albertensis [5], A. caldus [6], A. ferrivorans [7], A. ferridurans [8], A. ferriphilus [9], four of which also catalyze the dissimilatory oxidation of ferrous iron while three $(A$. thiooxidans, A. albertensis and A. caldus) do not.

Being capable of biogenic acid production and oxidation of reduced sulfur compounds, most species of the taxon have been exploited industrially in the recovery of

\footnotetext{
*Correspondence: rquatrini@cienciavida.org

${ }^{\dagger}$ Equal contributors

${ }^{1}$ Fundación Ciencia \& Vida, Av. Zañartu 1482, Santiago 7780272, Chile

Full list of author information is available at the end of the article
}

valuable metals such as copper and gold and other relevant elements from ores and wastes ([10] and references therein). Not only are they frequent members of most analyzed bioleaching consortia, but tend also to be numerically relevant ([11] and references therein). Due to their biotechnological relevance most species of the taxon have been the object of intensive research since the early 1900's [12]. Yet, despite compelling evidence regarding the widespread occurrence of $A$. albertensis [13-16] and its potential for chalcopyrite and sphalerite bioleaching [13, 17], A. albertensis remains the least studied species of all acidithiobacilli.

Whole genome sequences of a number of representative strains of four species of Acidithiobacillus ( $A$. thiooxidans, A. ferrooxidans, A. caldus and A. ferrivorans) have been reported to date [18] and genome comparisons have been performed both between and within species [19-23]. However, no representative genome sequence is yet available for A. albertensis. Given that $A$. albertensis resembles $A$. thiooxidans in several aspects of their biology and physiology [5, 24], and that presence of either species in the natural and industrial environments tend to be confounded due to the high similarity between species at the $16 \mathrm{~S}$ rRNA level 
[25], further characterization of the former is required to shed light into the species-specific processes. Availability of the whole-genome of the type strain of $A$. albertensis represents a first necessary step in this direction.

Here we present a description of the first draft of the genome sequence and annotation of the type strain of $A$. albertensis (DSM $14366^{\mathrm{T}}$ ) along with relevant genomic indices of the taxon. The data presented fill a longstanding gap in the understanding of the genomic landscape of the acidithiobacilli and of the biology of $A$. albertensis and paves the way for more encompassing phylogenomic analyses of the species complex of these fascinating model acidophiles.

\section{Organism information}

\section{Classification and features}

Originally described by Bryant and colleagues [5], A. albertensis (formerly Thiobacillus albertis) was recognized as a new species in 1988 [26]. The species epithet derives from the Latin (al.ber.ten'sis. M.L. adj. albertensis Alber$\tan )$, meaning pertaining to Alberta, a province of Canada, from where it was first isolated. The type strain is DSM 14366/ATCC 35403. A. albertensis was described as a mesophilic, obligatory autotrophic sulfur-oxidizer that did not oxidize iron. Differentiating characteristics from other members of the acidithiobacilli include forming yellowish colonies on solid sulfur-containing media, a slightly larger cellular size, a tuft of polar flagella, a glycocalyx and a number of large intracellular sulfur globules [5, 17]. A. albertensis was reported to have a more confined $\mathrm{pH}$ range for growth (2-4.5) and a slightly higher temperature growth optimum with respect to other members of the genus [1], although these features may vary between strains [17]. Additional properties of $A$. albertensis are listed in Table 1.

Phylogenetic analysis of the $16 \mathrm{~S}$ rRNA gene sequence of $A$. albertensis DSM $14366^{\mathrm{T}}$ places the type strain close to a few other cultivated members of the species and several uncultured clones deposited in GenBank, all of which are $100 \%$ identical at the $16 \mathrm{~S}$ rRNA gene level (Fig. 1). The A. albertensis type strain and its closest relatives branch apart from $A$. thiooxidans ${ }^{\mathrm{T}}$.

\section{Genome sequencing information Genome project history}

The organism was selected for sequencing on the basis of its phylogenetic position and 16S rRNA similarity to members of the genus Acidithiobacillus. This represents the first draft genome sequence of an $A$. albertensis strain. The Whole Genome Shotgun project has been deposited at GenBank under the accession MOAD00000000. The version described in
Table 1 Classification and general features of A. albertensis strain $^{\top}[22]$

\begin{tabular}{|c|c|c|c|}
\hline MIGS ID & Property & Term & $\begin{array}{l}\text { Evidence } \\
\text { code }^{\mathrm{a}}\end{array}$ \\
\hline & Classification & Domain Bacteria & TAS [1] \\
\hline & & Phylum Proteobacteria & TAS [1] \\
\hline & & Class Acidithiobacillia & TAS [2] \\
\hline & & Order Acidithiobacillales & TAS $[47,48]$ \\
\hline & & $\begin{array}{l}\text { Family } \\
\text { Acidithiobacillaceae }\end{array}$ & $\operatorname{TAS}[47,49]$ \\
\hline & & Genus Acidithiobacillus & TAS [1] \\
\hline & & $\begin{array}{l}\text { Species Acidithiobacillus } \\
\text { albertensis }\end{array}$ & $\operatorname{TAS}[5,26]$ \\
\hline & & $\begin{array}{l}\text { (Type) strain: Strain } \\
\text { (DSM 14366) }\end{array}$ & \\
\hline & Gram stain & Negative & TAS [5] \\
\hline & Cell shape & Rod & TAS [5] \\
\hline & Motility & Motile & TAS [5] \\
\hline & Sporulation & Not reported & NAS \\
\hline & Temperature range & $10-40^{\circ} \mathrm{C}$ & TAS [5] \\
\hline & $\begin{array}{l}\text { Optimum } \\
\text { temperature }\end{array}$ & $25-30^{\circ} \mathrm{C}$ & TAS [5] \\
\hline & pH range; Optimum & $2.0-4.5 ; 3.5-4.0$ & TAS [5] \\
\hline & Carbon source & $\mathrm{CO}_{2}$ & TAS [5] \\
\hline MIGS-6 & Habitat & $\begin{array}{l}\text { Acidic mineral-sulfur } \\
\text { rich environments }\end{array}$ & TAS [5] \\
\hline MIGS-6.3 & Salinity & Not reported & NAS \\
\hline MIGS-22 & Oxygen requirement & Aerobic & TAS [5] \\
\hline MIGS-15 & Biotic relationship & Free-living & NAS \\
\hline MIGS-14 & Pathogenicity & Non-pathogen & NAS \\
\hline MIGS-4 & Geographic location & Canada/Alberta & TAS [5] \\
\hline MIGS-5 & Sample collection & 1983 & TAS [5] \\
\hline MIGS-4.1 & Latitude & Not reported & NAS \\
\hline MIGS-4.2 & Longitude & Not reported & NAS \\
\hline MIGS-4.4 & Altitude & Not reported & NAS \\
\hline
\end{tabular}

${ }^{a}$ Evidence codes - IDA Inferred from Direct Assay, TAS: Traceable Author Statement (i.e., a direct report exists in the literature), NAS Non-traceable Author Statement (i.e., not directly observed for the living, isolated sample, but based on a generally accepted property for the species, or anecdotal evidence). These evidence codes are from the Gene Ontology project [50]

this paper consists of 1 scaffold $(2.7>\mathrm{X} \mathrm{Mbp})$ and 140 smaller contigs and is the first version, MOAD01000000. Table 2 presents the project information and its association with MIGS (version 2.0) compliance [27].

Growth conditions and genomic DNA preparation

A. albertensis strain DSM $14366^{\mathrm{T}}$ was obtained from the DSMZ collection and grown in DSMZ 71 medium at $30{ }^{\circ} \mathrm{C}$. DNA isolation and routine manipulations were carried out following standard protocols [28]. 


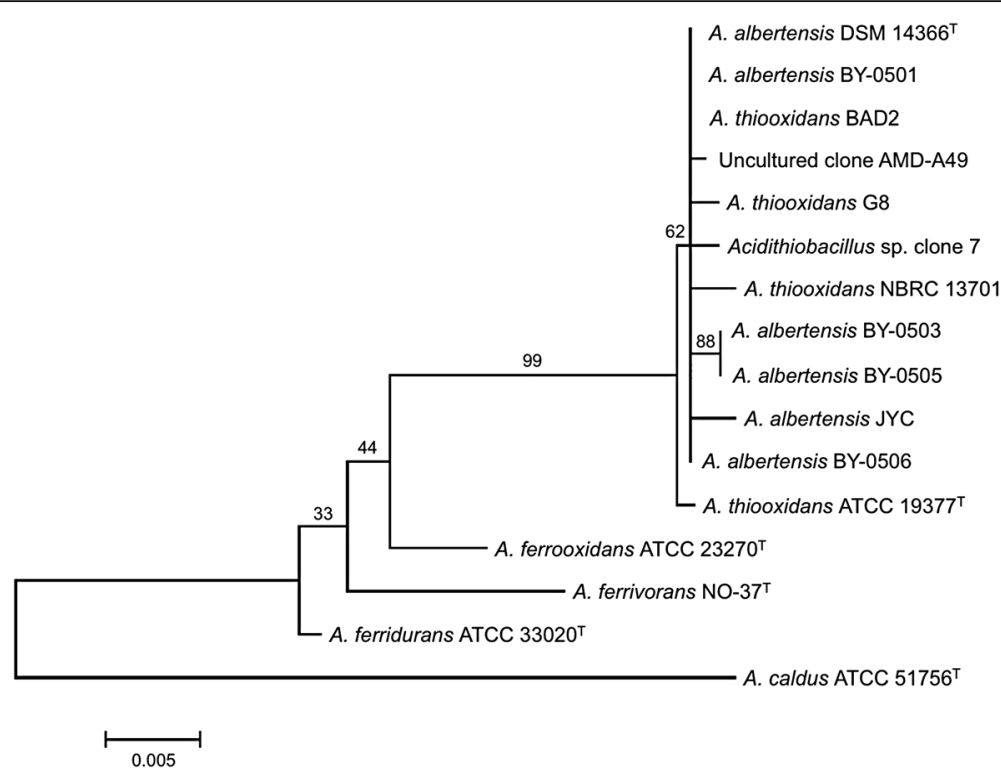

Fig. 1 Phylogenetic tree based on $16 \mathrm{~S}$ rDNA sequence information position of A. albertensis strain DSM $14366^{\top}$ (type strain $={ }^{\top}$ ) relative to other type and non-type strains within the acidithiobacilli. The strains and their corresponding GenBank accession numbers for 165 rRNA genes are: $A$. albertensis DSM 14366', NR_028982; A. albertensis BY0501, FJ032185; A. albertensis BY0503, FJ032186; A. albertensis BY0505, FJ032187; A. albertensis BY0506, GQ254658; A. albertensis JYC, FJ172635; A. thiooxidans ATCC 19377' , Y11596; A. thiooxidans BAD2, KC902821; A. thiooxidans G8, KC902819; A. thiooxidans NBRC13701, AY830902, AMD uncultured clone C7, JX989232; A. ferrooxidans ATCC 23270', NR_074193; A. ferrivorans NO-37, NR_114620; A. ferridurans ATCC $33020^{\top}$, NR_117036; A. caldus ATCC 51756 ${ }^{\top}$, CP005986. The tree was inferred using the Neighbor-Joining method [51]. The optimal tree with the sum of branch length $=0.08720008$ is shown. The percentage of replicate trees in which the associated taxa clustered together in the bootstrap test (1000 replicates) are shown next to the branches. The tree is drawn to scale, with branch lengths in the same units as those of the evolutionary distances used to infer the phylogenetic tree. The evolutionary distances were computed using the Maximum Composite Likelihood method [52] and are in the units of the number of base substitutions per site. The analysis involved 34nucleotide sequences. There were a total of 1314 positions in the final dataset. Evolutionary analyses were conducted in MEGA6 [53]

\section{Genome sequencing and assembly}

The genome of $A$. albertensis DSM $14366^{\mathrm{T}}$ was sequenced using Illumina sequencing technology (MiSeq platform) and paired-end libraries. Duplicate high quality libraries with insert sizes of $\sim 460$ bp were

Table 2 Project information

\begin{tabular}{lll}
\hline MIGS ID & Property & Term \\
\hline MIGS 31 & Finishing quality & Draft \\
MIGS-28 & Libraries used & Nextera 2.1 \\
MIGS 29 & Sequencing platforms & Illumina MiSeq \\
MIGS 31.2 & Fold coverage & $64 \times$ \\
MIGS 30 & Assemblers & Velvet v 1.2.10 \\
MIGS 32 & Gene calling method & Glimmer 3.02 \\
& Locus Tag & BLW97 \\
& Genbank ID & MOAD00000000 \\
& GenBank Date of Release & FEB 15, 2017 \\
& GOLD ID & Gp0225628 \\
& BIOPROJECT & PRJNA351776 \\
MIGS 13 & Source Material Identifier & DSM 14366 \\
& Project relevance & Biomining, Tree of life \\
\hline
\end{tabular}

prepared using Nextera ${ }^{\mathrm{T}}{ }^{\mathrm{M}}$ DNA Sample Preparation kit (Nextera, USA). Raw sequencing reads were preprocessed using Trimmomatic v0.32 [29]. Only reads with a quality score $>$ Q30 (corresponding to less than 1 error per $1000 \mathrm{bp}$ ) and a read length $>35 \mathrm{nt}$ were retained. High quality reads were assembled de novo using Velvet (v1.2.10) [30] and a k-mer length of 151, with an N50 of 39,225. Contig segments with at least 37 fold coverage were further scaffolded. The final draft assembly contained 1 scaffold $(2.7>\mathrm{X} \mathrm{Mbp})$ and 140 smaller contigs. The total size of the draft genome is $\sim 3.1 \mathrm{Mbp}$ and the final assembly is based on $3.1 \mathrm{Gbp}$ of Illumina data.

\section{Genome annotations}

Genes were identified using Glimmer 3.02 [31] as part of the RAST annotation pipeline [32]. The tRNA and tmRNA predictions were made using ARAGORN v1.2.36 [33] and the rRNA prediction was carried out via HMMER3 [34]. Additional gene prediction analysis and manual functional annotation curation was performed using in house resources. The predicted CDSs were used to search the National Center for Biotechnology Information non-redundant database, UniProt, TIGRFam, 
Pfam, PRIAM, KEGG, COG and InterPro databases. Protein coding genes were analyzed for signalpeptides using SignalP v4.1 [35] and transmembrane helices using TMHMM v2.0 [36]. The circular map was drawn with CGView [37]. Single nucleotide polymorphisms were called using SNAP v2.1.1 [www.hiv.lanl.gov/content/sequence/SNAP/SNAP.html]. Non-synonymous substitution rates were calculated as the proportion between the number of observed synonymous substitutions in pairwise gene alignments and the size of the each alignment, and are expressed in percent.

Genome comparisons were performed using the GET_HOMOLOGUES software package (version 07112016). Orthology was determined based on all-versus-all Best Bidirectional BlastP Hit and COGtriangles v2.1 as clustering algorithm. Pairwise alignment cutoffs were set at $75 \%$ coverage and $E$-value of $10 \mathrm{E}-5$. The phylogenomic relationships between the A. albertensis $^{\mathrm{T}}$ and other Acidithiobacillus strains were inferred from the average nucleotide identity (ANI) values assessed by BLASTn [38] and the in silico
DNA-DNA hybridization indexes (DDH) assessed using the Genome-to-Genome Distance Calculator with recommended formula 2 [39]. Species cutoff limits were those defined by Meier-Kolthoff and colleagues [40].

\section{Genome properties}

The 3.5 Mbp draft genome of $A$. albertensis ${ }^{\mathrm{T}}$ is currently arranged into one high quality scaffold (Fig. 2) and 140 smaller contigs, most of which correspond to fragments of plasmids and other mobile genetic elements. According to the criteria of conservation of universal housekeeping genes [41], the genome is predicted to be $99.9 \%$ complete. Its average $\mathrm{G}+\mathrm{C}$ content is $52.5 \%$ (Table 3 ). From a total of 3202 predicted genes, 3149 were protein-coding genes and 53 were RNA genes. A total of $63.4 \%$ of the CDSs were assigned a putative function while the remainders were annotated as hypotheticals. A total of 53 RNA genes partitioned into 47 tRNAs, 1 tmRNA and 2 rRNA operons (Table 3). The presence of two rRNA operons has recently been experimentally

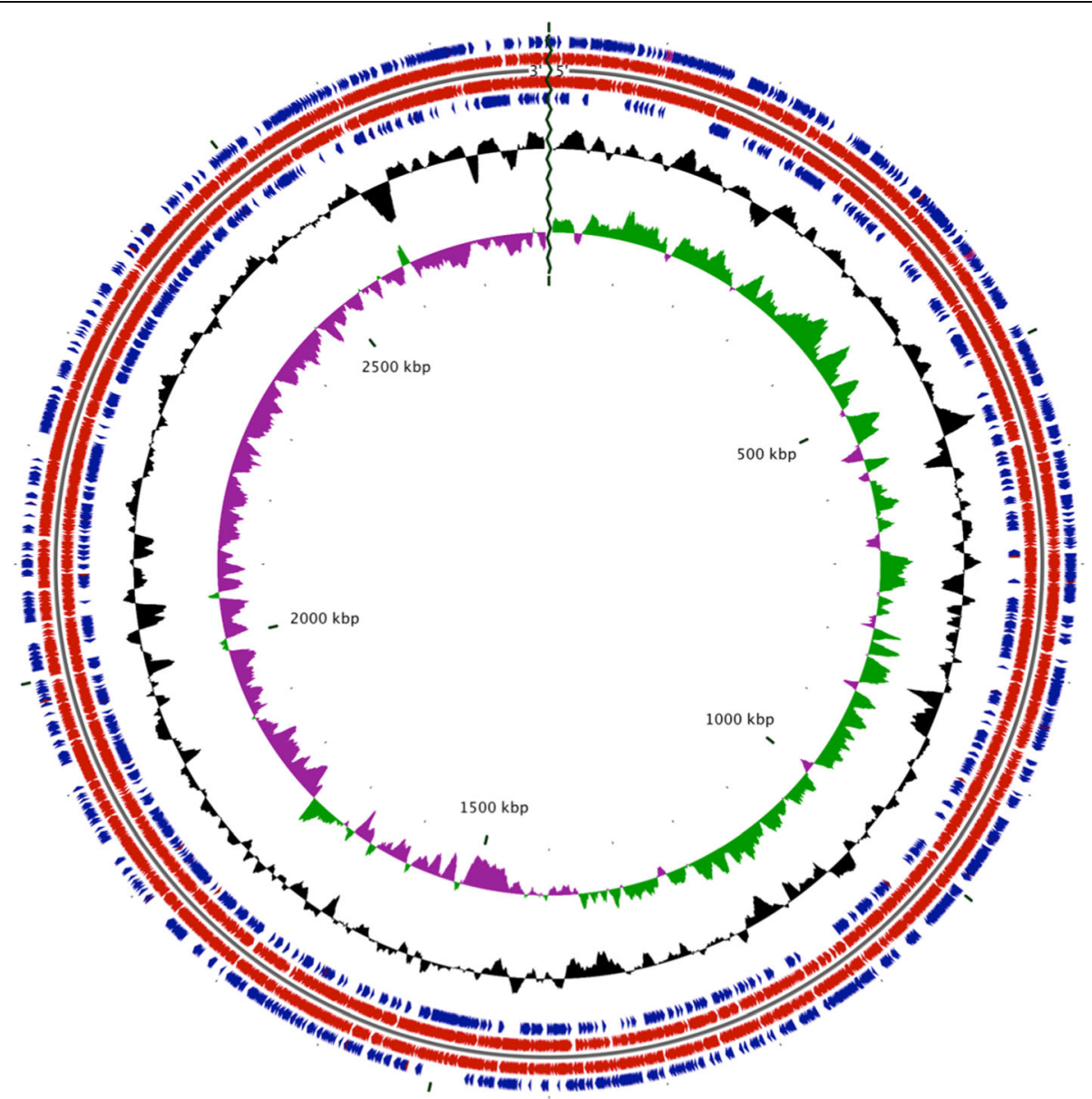

Fig. 2 Circular representation of the high quality draft genome of A. albertensis ${ }^{\top}$ displaying relevant genome features. The features are the following (from outside to inside): Genes on forward strand (red); Genes on reverse strand (red); CDSs (blue), GC content (black); GC skew (green and purple) 
Table 3 Genome statistics

\begin{tabular}{|c|c|c|}
\hline Attribute & Value & $\%$ of Total ${ }^{a}$ \\
\hline Genome size (bp) & $3,497,418$ & 100.00 \\
\hline DNA coding (bp) & $2,930,787$ & 83.80 \\
\hline DNA G + C (bp) & $1,836,144$ & 52.50 \\
\hline DNA scaffolds & 141 & 100.00 \\
\hline Total genes ${ }^{\mathrm{b}}$ & 3202 & 100.00 \\
\hline Protein coding genes & 3149 & 98.34 \\
\hline RNA genes $^{c}$ & 53 & 1.66 \\
\hline Pseudo genes & n.d & n.d \\
\hline Genes in internal clusters & n.d & n.d \\
\hline Genes with function prediction & 1967 & 61.43 \\
\hline Genes assigned to COGs & 2322 & 72.52 \\
\hline Genes with Pfam domains & 2152 & 67,21 \\
\hline Genes with signalpeptides & 374 & 11.68 \\
\hline Genes with transmembrane helices & 727 & 22.70 \\
\hline CRISPR repeats & 0 & 0 \\
\hline
\end{tabular}

${ }^{a}$ The total is based on either the size of the genome in base pairs or the total number of genes in theannotated genome

Includes tRNA, tmRNA, rRNA

Includes 23S, 16S and 5S rRNA

validated [25]. According to the genomic sequence information, the two operons are $100 \%$ identical. The distribution of genes into COGs functional categories is presented in Table 4.

\section{Insights from the genome sequence}

Metabolic reconstruction analysis revealed a complete suite of genes for sulfur oxidation, including those encoding the SOX complex (soxYZB-AX and sox $Y Z A-B$, sox $H)$, tetrathionate hydrolase $(\operatorname{tet} H, \operatorname{dox} D)$ and heterodisulfide reductase ( $h d r B C$ and $h d r A B C$ ) previously found in $A$. thiooxidans $^{\mathrm{T}}$ and $A$. caldus $^{\mathrm{T}}[42,43]$. Multiple copies of cytochrome d (cydAB) and cytochrome o (cyoACBD) terminal oxidases found in professional sulfur-oxidizing acidithiobacilli [19], also occur in $A$. albertensis $^{\mathrm{T}}$. Genes for carbon dioxide fixation are well conserved, but no genes for nitrogen fixation were detected in the draft genome. Instead, genes for nitrate/nitrite assimilation and urea hydrolysis, both resulting in the production of ammonia, were found in the genome of the $A$. albertensis ${ }^{\mathrm{T}}$, along with a number of ammonia transporters.

Gene clusters for the biosynthesis and assembly of flagella, which is a differential morphologic trait between this species and $A$. thiooxidans, are conserved with respect to those encoded in the latter, in both general architecture and gene content. The pairwise identity between the predicted protein products of the flagellar genes of both type strains ranges from 87 to $100 \%$, suggesting as well, the common ancestry of the operons.
Table 4 Number of genes associated with general COG functional categories

\begin{tabular}{llll}
\hline Code & Value & \%age & Description \\
\hline J & 135 & 4.22 & Translation \\
K & 1 & 0.03 & RNA processing and modification \\
L & 124 & 3.87 & Transcription \\
B & 181 & 5.65 & Replication, recombination and repair \\
D & 1 & 0.03 & Chromatin structure and dynamics \\
Y & 29 & 0.91 & Cell cycle control, mitosis and meiosis \\
V & 0 & 0.00 & Nuclear structure \\
T & 52 & 1.62 & Defense mechanisms \\
M & 127 & 3.97 & Signal transduction mechanisms \\
N & 203 & 6.34 & Cell wall/membrane biogenesis \\
Z & 66 & 2.06 & Cell motility \\
W & 0 & 0.00 & Cytoskeleton \\
U & 102 & 0.00 & Extracellular structures \\
O & 104 & 3.19 & Intracellular trafficking and secretion \\
& 3.25 & Posttranslational modification, protein \\
C & 169 & 5.28 & turnover, chaperones \\
G & 113 & 3.53 & Carbohy production and conversion \\
E & 156 & 4.87 & Amino acid transport and metabolism \\
F & 53 & 1.66 & Nucleotide transport and metabolism \\
H & 102 & 3.19 & Coenzyme transport and metabolism \\
I & 57 & 1.78 & Lipid transport and metabolism \\
P & 109 & 3.40 & Inorganic ion transport and metabolism \\
Q & 37 & 1.16 & Secondary metabolites biosynthesis, \\
R & 222 & 6.93 & General function prediction only \\
S & 179 & 5.60 & Function unknown \\
\hline & 880 & 27,48 & Not in CoGs \\
\hline
\end{tabular}

The total is based on the total number of predicted protein coding genes in the annotated genome

Yet, a relevant number of SNPs (single nucleotide polymorphisms) producing non-synonymous amino acidic substitutions of presently unclear relevance were uncovered in nine genes of the A. albertensis ${ }^{\mathrm{T}}$ flagellar cluster (Fig. 3), namely: flaB2, flhF, flhG, fliH, fliK, fliR, fliS2, fleS and fleQ1. All these genes are well conserved between $A$. thiooxidans strains (Fig. 3). The gene variants identified in $A$. albertensis were validated by read recruitment on a one-to-one basis, and are supported by more than 75 fold average (deep) coverage. These genes encode the flagellins FlaB2, the hook-length control protein FliK, the biosynthesis proteins FlhF, FliR and FliS, the biosynthesis regulator FlhG, also known as $\mathrm{FleN}$, the assembly protein $\mathrm{FliH}$, the sensor histidine kinase FleS and the regulator FleQ. Among these proteins, FlhF and FlhG/FleN encode proteins that have 


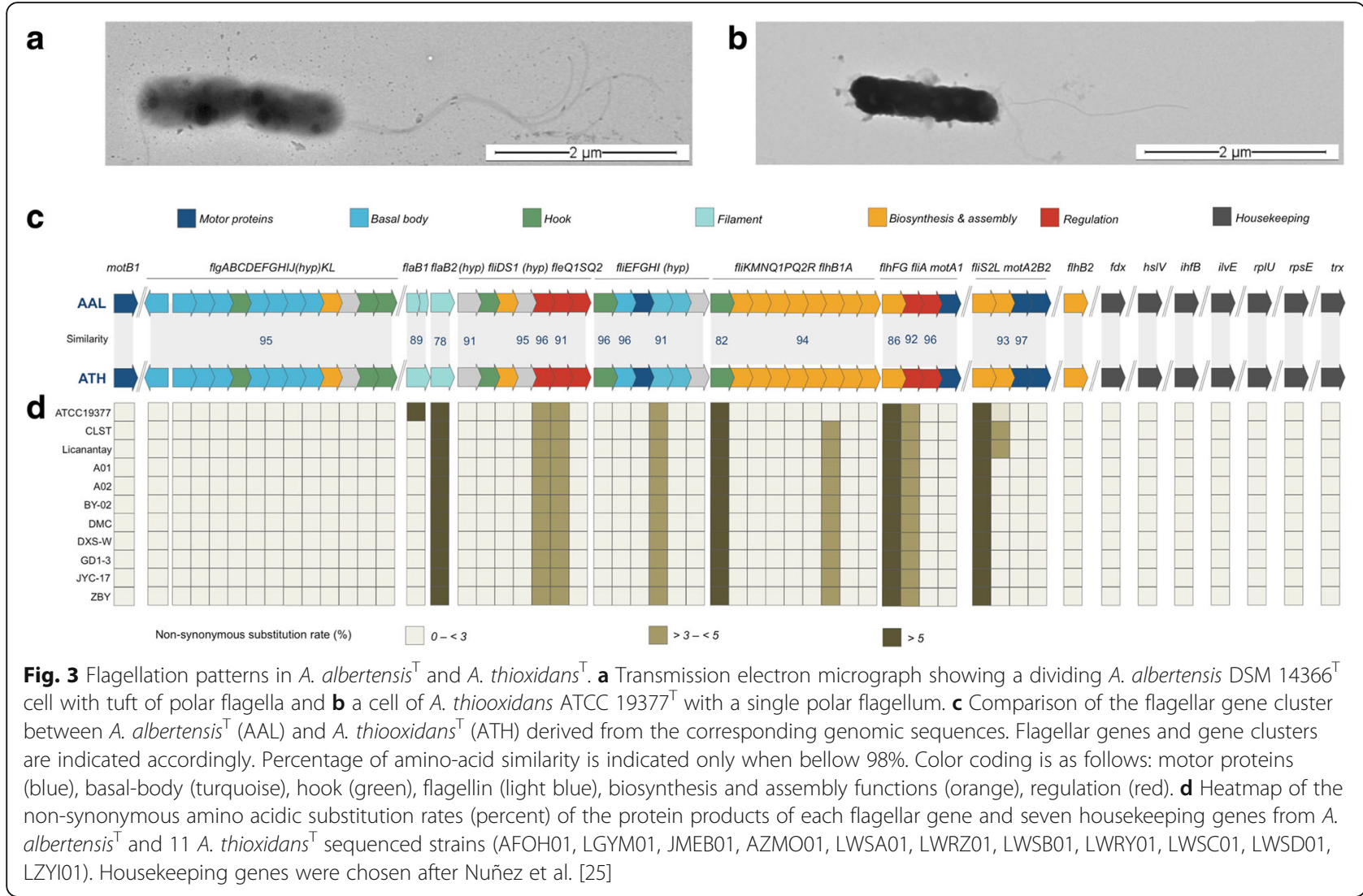

been shown to be relevant in the control flagellation patterns in other model bacteria [44], suggesting that differences in flagellation between A. albertensis (lophotrichous) and $A$. thiooxidans (monotrichous) shown in Fig. 3 might be partially attributed to divergence in these genes $(6-14 \%)$. For the rest of the flagellar genes the rate of SNPs conductive to amino acidic substitutions between $A$. albertensis and other $A$. thiooxidans sequenced strains is low $(<3)$ and similar to the rate observed in well conserved housekeeping genes. Further studies should be pursued to clarify the relevance of the uncovered substitutions in the flagellation patterns of the acidithiobacilli. Also, a larger number of chemotaxis genes were predicted in the $A$. albertensis ${ }^{\mathrm{T}}$ genome sequence with respect to those in $A$. thiooxidans. This latter set of genes is organized in a cluster that includes mcp1-cheYSA$m c p 2-c h e W R D B$, and encodes proteins participating in sensory adaptation to changing environmental signals rather than flagellar motor control [45].

Differences between the A. albertensis ${ }^{T}$ genome and the pangenome of 10 other sequenced $A$. thiooxidans (recently reported by [22]) can be attributed to little over 1000 genes (1066 genes). Nearly half of these genes pertain to at least 10 integrated mobile genetic elements and a presently unclear number of plasmids, representing up to $16.2 \%$ of the $A$. albertensis ${ }^{T}$ genome. In these genomic segments $54.5 \%$ of the genes are hypotheticals but a number of relevant functions were also detected, including among others: a) four orthologs of the sulfur oxygenase reductases (sor 1-4), b) the gene cluster encoding the assimilatory nitrate and nitrite reductases, c) the urea carboxylase/allophanate hydrolase and the urea $\mathrm{ABC}$ transporter encoding genes, $\mathrm{d}$ ) the spermidine/putrescine $\mathrm{ABC}$ transporter pot $A B C$ and e) the three-gene operon associated with rubrerythrin, recently described by Cárdenas et al. [46]. All of these functions could confer adaptive advantages to A. albertensis ${ }^{\mathrm{T}}$ over A. thiooxidans strains under nitrogen and oxygen limitation and/or under extremely low $\mathrm{pH}$.

Differences in gene dosage have also been observed between the two mesophilic sulfur-oxidizing/non ironoxidizing species based on the comparison of the two type strains. A. albertensis ${ }^{\mathrm{T}}$ has more copies or gene variants (2 to more than 30) of the following: a) transposases and inactivated derivatives, b) thiol:disulfide interchange protein DsbG precursor, c) methyl-accepting chemotaxis receptor proteins, d) Crp/Fnr, LysR and MerR family transcriptional regulators, e) cytochrome d ubiquinol oxidases and e) SOR sulfur oxygenase reductases. The latter occur in four copies in the $A$. albertensis $^{\mathrm{T}}$ genome, being completely absent in A. thiooxidans ${ }^{\mathrm{T}}$. Also more than 30 predicted protein products with GGDEF/EAL domains, likely involved in 
nucleotide driven signaling pathways, control and modulate gene expression and/or activity in A. albertensis ${ }^{\mathrm{T}}, 40 \%$ of which seem to be exclusive to this species. Significant quantitative and qualitative differences in gene content have been reported before between strains of $A$. thiooxidans obtained from industrial processes [21, 22].

Despite the above mentioned differences between the type strains of $A$. albertensis and $A$. thiooxidans, the average nucleotide identity value assessed by BLASTn $(97,4 \%)$ and the in silico DNA-DNA hybridization index assessed by GGDC $(82.9 \%)$ are bellow the currently recognized species cutoff limits [39], implying that $A$. albertensis and $A$. thiooxidans probably comprise a single genospecies.

\section{Conclusions}

Altogether, the evidence presented herein suggests that validity of $A$. albertensis as an independent species should be reconsidered. In this respect, genomic approaches are crucial for understanding evolutionary processes and the origins of microbial biodiversity. The availability of the first high quality draft genome sequence of an $A$. albertensis strain will certainly enable more comprehensive comparative genomic studies and contribute to the resolution of the taxonomy and phylogeny of the genus. From a genomic standpoint, further analyses should be performed to assess if existing differences between the two type strains extend to other strains of each 'presumed species'.

\section{Abbreviations}

ATCC: American Type Culture Collection; DSMZ: Deutsche Sammlung von Mikroorganismen und Zellkulturen; NCBI: National Center for Biotechnology Information

\section{Funding}

This work was performed under the auspices of the projects FONDECYT 1140048 and FONDECYT 1130683 and Basal PFB-16. We would like to acknowledge also FONDECYT Post Doctoral research funds (FONDECYT 3140003 and 3130376) and CONICYT and UNAB scholarships.

\section{Authors' contributions}

$R Q, D B J$ and DSH conceived and supervised the study. PCC and GE prepared the libraries and ran the sequencing. MC and $\mathrm{AM}$ carried out the sequence processing and the bioinformatic analysis. JPC did the phylogenetic analysis. LA grew the cultures and prepared high quality DNA. MG prepared and maintained the strains. Fl and HN supported the sequence analyses. MC, AM and $R Q$ analyzed and interpreted the data and wrote the paper. All authors read and approved the final manuscript.

\section{Competing interests}

The authors declare that they have no competing interests.

\section{Publisher's Note}

Springer Nature remains neutral with regard to jurisdictional claims in published maps and institutional affiliations.

\section{Author details}

${ }^{1}$ Fundación Ciencia \& Vida, Av. Zañartu 1482, Santiago 7780272, Chile. ${ }^{2}$ Genómica S.p.A, Santiago, Chile. ${ }^{3}$ Facultad de Ciencias Biologicas, Universidad Andres Bello, Santiago, Chile. ${ }^{4}$ College of Natural Sciences,
Bangor University, Bangor, UK. ${ }^{5}$ Current Address: uBiome Chile, SpA, Santiago, Chile.

Received: 21 April 2017 Accepted: 21 November 2017

Published online: 15 December 2017

\section{References}

1. Kelly DP, Wood AP. Reclassification of some species of Thiobacillus to the newly designated genera Acidithiobacillus gen. nov., Halothiobacillus gen. nov. and Thermithiobacillus gen. nov. Int J Syst Evol Microbiol. 2000; doi:10.1099/00207713-50-2-511.

2. Williams KP, Kelly DP. Proposal for a new class within the phylum Proteobacteria, Acidithiobacillia classis nov., with the type order Acidithiobacillales, and emended description of the class Gammaproteobacteria. Int J Syst Evol Microbiol. 2013; doi:10.1099/ijs.0.049270-0.

3. Waksman SA, Joffe JS. Microorganisms concerned in the oxidation of sulfur in the soil. II. Thiobacillus thiooxidans, a new sulfur-oxidizing organism isolated from the soil. J Bacteriol. 1922; PMC http://www.ncbi.nlm.nih.gov/pmc/articles/ PMC378965. Accessed 1922

4. Temple KL, Colmer AR. The autotrophic oxidation of iron by a new bacterium: Thiobacillus ferrooxidans. J Bacteriol. 1951; PMC http://www.ncbi. nlm.nih.gov/pmc/articles/PMC386175. Accessed 1951.

5. Bryant RD, McGroarty KM, Costerton JW, Laishley EJ. Isolation and characterization of a new acidophilic Thiobacillus species (T. albertis). Can J Microbiol. 1983; doi:10.1139/m83-178

6. Hallberg KB, Lindström EB. Characterization of Thiobacillus caldus sp. nov., a moderately thermophilic acidophile. Microbiology. 1994; doi:10.1099/13500872140-12-3451.

7. Hallberg KB, González-Toril E, Johnson DB. Acidithiobacillus ferrivorans sp nov.; facultatively anaerobic, psychrotolerant iron-, and sulfur-oxidizing acidophiles isolated from metal mine-impacted environments. Extremophiles. 2010; doi:10.1007/s00792-009-0282-y.

8. Hedrich S, Johnson DB. Acidithiobacillus ferridurans sp. nov., an acidophilic ironsulfur- and hydrogen-metabolizing chemolithotrophic gammaproteobacterium. Int J Syst Evol Microbiol. 2013; doi:10.1099/ijs.0.049759-0.

9. Falagán C, Johnson DB. Acidithiobacillus ferriphilus sp. nov., a facultatively anaerobic iron- and sulfur-metabolizing extreme acidophile. Int J Syst Evol Microbiol. 2016; doi:10.1099/ijsem.0.000698.

10. Johnson DB. Biomining-biotechnologies for extracting and recovering metals from ores and waste materials. Curr Opin Biotechnol. 2014; doi:10. 1016/j.copbio.2014.04.008.

11. Nuñez H, Covarrubias PC, Moya-Beltrán A, Issotta F, Atavales J, Acuña LG, Johnson DB, Quatrini R. Detection, identification and typing of species and strains: a review. Res Microbiol. 2016; doi:10.1016/j.resmic.2016.05.006.

12. Johnson DB, Quatrini R. Acidophile microbiology in space and time. In: Quatrini R, Johnson DB, editors. Acidophiles: life in extremely acidic environments. UK: Caister Academic Press; 2016. p. 3-16. 10.21775/9781910190333.01.

13. Kelly DP, Harrison AH. Genus Thiobacillus. In: Staley JT, Bryant MP, Pfennig N, Holt JG, editors. Bergey's manual of systematic bacteriology. Baltimore: Williams \& Wilkins; 1989. p. 1842-58.

14. Puhakka AJ, Kaksonen AH, Riekkola-Vanhanen M. Heap leaching of black schist. In: Rawlings DE, Johnson BD, editors. Biomining. Berlin, Heidelberg, New York: Springer; 2007. p. 139-50.

15. Urbieta MS, González-Toril E, Aguilera A, Giaveno MA, Donati E. First prokaryotic biodiversity assessment using molecular techniques of an acidic river in Neuquén, Argentina. Microb Ecol. 2012; doi:10.1007/s00248-011-9997-2.

16. Smeulders MJ, Pol A, Zandvoort MH, Jetten MS, Op den Camp HJ. Diversity and ecophysiology of new isolates of extremely acidophilic CS2-converting Acidithiobacillus strains. Appl Environ Microbiol. 2013; doi:10.1128/AEM.02167-13.

17. Xia JL, Peng AA, He H, Yang Y, Liu XD, Qiu GZ. A new strain Acidithiobacillus albertensis BY-05 for bioleaching of metal sulfides ores. Trans Nonferrous Metal Soc China. 2007; doi:10.1016/S1003-6326(07)60067-3.

18. Cárdenas JP, Quatrini R, Holmes DS. Progress in acidophile genomics. In: Quatrini R, Johnson DB, editors. Acidophiles: life in extremely acidic environments. UK: Caister Academic Press; 2016a. p. 179-97.

19. Valdés J, Cárdenas JP, Quatrini R, Esparza M, Osorio H, Duarte F, et al. Comparative genomics begins to unravel the ecophysiology of bioleaching. Hydrometallurgy. 2010; doi:10.4028/www.scientific.net/AMR.71-73.143.

20. Acuña LG, Cárdenas JP, Covarrubias PC, Haristoy JJ, Flores R, Nuñez H, et al. Architecture and gene repertoire of the flexible genome of the extreme 
acidophile Acidithiobacillus caldus. PLoS One. 2013; doi:10.1371/journal.pone. 0078237.

21. Travisany D, Cortés MP, Latorre M, Di Genova A, Budinich M, BobadillaFazzini RA, et al. A new genome of Acidithiobacillus thiooxidans provides insights into adaptation to a bioleaching environment. Res Microbiol. 2014; doi:10.1016/j.resmic.2014.08.004.

22. Zhang $X$, Feng $X$, Tao J, Ma L, Xiao Y, Liang Y, et al. Comparative genomics of the extreme Acidophile Acidithiobacillus thiooxidans reveals intraspecific divergence and niche adaptation. Int J Mol Sci. 2016a; doi:10.3390/ijms17081355.

23. Zhang X, She S, Dong W, Niu J, Xiao Y, Liang Y, et al. Comparative genomics unravels metabolic differences at the species and/or strain level and extremely acidic environmental adaptation of ten bacteria belonging to the genus Acidithiobacillus. Syst Appl Microbiol. 2016b; doi:10.1016/j. syapm.2016.08.007.

24. Bryant RD, Costerton JW, Laishley EJ. The role of Thiobacillus albertis glycocalyx in the adhesion of cells to elemental sulfur. Can J Microbiol. 1984; doi:10.1139/m84-015.

25. Nuñez H, Moya-Beltrán A, Covarrubias PC, Issotta F, Cárdenas JP, González $\mathrm{M}$, et al. Molecular systematics of the genus Acidithiobacillus: insights into the phylogenetic structure and diversification of the taxon. Front Microbiol. 2017; doi:10.3389/fmicb.2017.00030.

26. Anon. Validation of the publication of new names and new combinations previously effectively published outside the IJSB. List No. 25. Int J Syst Bacteriol. 1988; doi:10.1099/00207713-38-2-220.

27. Field D, Garrity G, Gray T, Morrison N, Selengut J, Sterk P, et al. The minimum information about a genome sequence (MIGS) specification. Nat Biotechnol. 2008; doi:10.1038/nbt1360.

28. Nieto PA, Covarrubias PC, Jedlicki E, Holmes DS, Quatrini R. Selection and evaluation of reference genes for improved interrogation of microbial transcriptomes: case study with the extremophile Acidithiobacillus ferrooxidans. BMC Mol Biol. 2009; doi:10.1186/1471-2199-10-63.

29. Bolger AM, Lohse M, Usadel B. Trimmomatic: a flexible trimmer for Illumina sequence data. Bioinformatics. 2014; doi:10.1093/bioinformatics/btu170.

30. Zerbino DR, Birney E. Velvet: algorithms for de novo short read assembly using de Bruijn graphs. Genome Res. 2008; doi:10.1101/gr.074492.107.

31. Delcher AL, Bratke KA, Powers EC, Salzberg SL. Identifying bacterial genes and endosymbiont DNA with glimmer. Bioinformatics. 2007; doi:10.1093/ bioinformatics/btm009.

32. Overbeek R, Olson R, Pusch GD, Olsen GJ, Davis JJ, Disz T, et al. The SEED and the Rapid Annotation of microbial genomes using Subsystems Technology (RAST). Nucleic Ac Res. 2014; doi:10.1093/nar/gkt1226.

33. Laslett $D$, Canback B. ARAGORN, a program to detect tRNA genes and tmRNA genes in nucleotide sequences. Nucleic Acids Res. 2004; doi:10.1093/nar/gkh152.

34. Huang Y, Gilna P, Li W. Identification of ribosomal RNA genes in metagenomic fragments. Bioinformatics. 2009; doi:10.1093/bioinformatics/btp161.

35. Petersen TN, Brunak S, von Heijne G, Nielsen H. SignalP 4.0: discriminating signal peptides from transmembrane regions. Nat Methods. 2011; doi:10.1038/nmeth.1701.

36. Krogh A, Larsson B, von Heijne G, Sonnhammer EL. Predicting transmembrane protein topology with a hidden Markov model: application to complete genomes. J Mol Biol. 2001; doi:10.1006/jmbi.2000.4315.

37. Stothard P, Wishart DS. Circular genome visualization and exploration using CGView. Bioinformatics. 2005; doi:10.1093/bioinformatics/bti054.

38. Goris J, Konstantinidis KT, Klappenbach JA, Coenye T, Vandamme P, Tiedje JM. DNA-DNA hybridization values and their relationship to whole-genome sequence similarities. Int J Syst Evol Microbiol. 2007; doi:10.1099/ijs.0.64483-0.

39. Meier-Kolthoff JP, Auch AF, Klenk HP, Göker M. Genome sequence-based species delimitation with confidence intervals and improved distance functions. BMC Bioinformatics. 2013; doi:10.1186/1471-2105-14-60.

40. Meier-Kolthoff JP, Hahnke RL, Petersen J, Scheuner C, Michael V, Fiebig A, et al. Complete genome sequence of DSM $30083^{\top}$, the type strain $\left(U 5 / 41^{\top}\right)$ of Escherichia coli, and a proposal for delineating subspecies in microbial taxonomy. Stand Genomic Sci. 2014; doi:10.1186/1944-3277-9-2.

41. Raes J, Korbel JO, Lercher MJ, von Mering C, Bork P. Prediction of effective genome size in metagenomic samples. Genome Biol. 2007; do:10.1186/gb2007-8-1-r10.

42. Valdés J, Ossandon F, Quatrini R, Dopson M, Holmes DS. Draft genome sequence of the extremely acidophilic biomining bacterium Acidithiobacillus thiooxidans ATCC 19377 provides insights into the evolution of the Acidithiobacillus genus. J Bacteriol. 2011; doi:10.1128/JB.06281-11.
43. Valdés J, Quatrini R, Hallberg K, Dopson M, Valenzuela PD, Holmes DS. Draft genome sequence of the extremely acidophilic bacterium Acidithiobacillus caldus ATCC 51756 reveals metabolic versatility in the genus Acidithiobacillus. J Bacteriol. 2009; doi:10.1128/JB.00843-09.

44. Kazmierczak BI, Hendrixson DR. Spatial and numerical regulation of flagellar biosynthesis in polarly flagellated bacteria. Mol Microbiol. 2013; doi:10.1111/ mmi.12221.

45. Parkinson JS, Hazelbauer GL, Falke JJ. Signaling and sensory adaptation in Escherichia coli chemoreceptors: 2015 update. Trends Microbiol. 2015; doi:10.1016/j.tim.2015.03.003.

46. Cárdenas JP, Quatrini R, Holmes DS. Aerobic lineage of the oxidative stress response protein rubrerythrin emerged in an ancient microaerobic, (hyper)thermophilic environment. Front Microbiol. 2016b; doi:10.3389/fmicb. 2016.01822

47. Euzéby J. Validation List No. 106. Validation of publication of new names and new combinations previously effectively published outside the IJSEM. Int J Syst Evol Microbiol. 2005; doi:10.1099/ijs.0.64108-0.

48. Garrity GM, Bell JA, Lilburn T. Order II. Acidithiobacillales ord. nov. In: Brenner DJ, Krieg NR, Staley JT, Garrity GM, editors. Bergey's manual of systematic bacteriology, vol. 2, part B. 2nd ed. New York: Springer; 2005. p. 60.

49. Garrity GM, Bell JA, Lilburn T. Family I. Acidithiobacillaceae fam. nov. In: Brenner DJ, Krieg NR, Staley JT, Garrity GM, editors. Bergey's manual of systematic bacteriology, vol. 2, part B. 2nd ed. New York: Springer; 2005. p. 60.

50. Ashburner M, Ball CA, Blake JA, Botstein D, Butler H, Cherry JM, et al. Gene ontology: tool for the unification of biology. The gene ontology consortium. Nat Genet. 2000; doi:10.1038/75556.

51. Saitou N, Nei M. The neighbor-joining method: a new method for reconstructing phylogenetic trees. Mol Biol Evol. 1987;4:406-25.

52. Tamura K, Nei M, Kumar S. Prospects for inferring very large phylogenies by using the neighbor-joining method. Proc Natl Acad Sci U S A. 2004; doi:10. 1073/pnas.0404206101.

53. Tamura K, Stecher G, Peterson D, Filipski A, Kumar S. MEGA6: molecular evolutionary genetics analysis version 6.0. Mol Biol Evol. 2013; doi:10.1093/ molbev/mst197.

\section{Submit your next manuscript to BioMed Central and we will help you at every step:}

- We accept pre-submission inquiries

- Our selector tool helps you to find the most relevant journal

- We provide round the clock customer support

- Convenient online submission

- Thorough peer review

- Inclusion in PubMed and all major indexing services

- Maximum visibility for your research

Submit your manuscript at www.biomedcentral.com/submit

) Biomed Central 